\title{
The Anopheles community and the role of Anopheles minimus on malaria transmission on the China-Myanmar border
}

\author{
Guo Yu', Guiyun Yan², Naixin Zhang ${ }^{1}$, Daibin Zhong ${ }^{2}$, Ying Wang ${ }^{3}$, Zhengbo He ${ }^{1}$, Zhentian Yan ${ }^{1}$, Wenbo Fu', \\ Feilong Yang ${ }^{1}$ and Bin Chen ${ }^{1 *}$
}

\begin{abstract}
Background: Malaria around the China-Myanmar border is a serious health problem in the countries of South-East Asia. An. minimus is a principle malaria vector with a wide geographic distribution in this area. Malaria is endemic along the boundary between Yunnan province in China and the Kachin State of Myanmar where the local Anopheles community (species composition) and the malaria transmission vectors have never been clarified.

Methods: Adult Anopheles specimens were collected using CDC light traps in four villages along the border of China and Myanmar from May 2012 to April 2013. Morphological and molecular identification of mosquito adults confirmed the species of Anopheles. Blood-meal identification using the female abdomens was conducted using multiplex PCR. For sporozoite detection in An. minimus, sets of 10 female salivary glands were pooled and identified with SSU rDNA using nested PCR. Monthly abundance of An. minimus populations during the year was documented. The diversity of Anopheles and the role of An. minimus on malaria transmission in this border area were analyzed.

Results: 4,833 adult mosquitoes in the genus Anopheles were collected and morphologically identified to species or species complex. The Anopheles community is comprised of 13 species, and $78.83 \%$ of our total specimens belonged to An. minimus s.l., followed by An. maculatus (5.55\%) and the An. culicifacies complex (4.03\%). The quantity of trapped An. minimus in the rainy season of malaria transmission was greater than during the non-malarial dry season, and a peak was found in May 2012. An. minimus fed on the blood of four animals: humans (79.8\%), cattle (10.6\%), pigs (5.8\%) and dogs (3.8\%). 1,500 females of An. minimus were pooled into 150 samples and tested for sporozoites: only 1 pooled sample was found to have sporozoites of Plasmodium vivax.

Conclusion: Anopheles is abundant with An. minimus being the dominant species and having a high human blood index along the China-Myanmar border. The sporozoites in An. minimus were determined to be Plasmodium vivax with a $0.07-0.7 \%$ infection rate.
\end{abstract}

Keywords: Anopheles community, An. minimus, Blood meal, Plasmodium vivax, China-Myanmar border

\section{Background}

According to the World Malaria Report 2012, the estimated annual malaria incidence in the World and in South-East Asia for 2010 were 219 million and 32 million cases, resulting in 660,000 and 43,000 deaths, respectively [1]. Within SE Asia, the Greater Mekong Subregion (GMS) has been one of the most dangerous foci for malaria [2].

\footnotetext{
*Correspondence: c_bin@hotmail.com

'Institute of Entomology and Molecular Biology, College of Life Sciences, Chongqing Normal University, Chongqing, P.R. China

Full list of author information is available at the end of the article
}

Nabang town established in 1996 is located in the western part of Yingjiang prefecture in the Yunnan province of China. It is a burgeoning treaty port with a total permanent resident population of 1,622 in 2010 and has a shared border with Lazan city in the Kachin state of Myanmar. A total of 372 malaria cases were confirmed by microscopic blood examination from this GMS border region between April and December in 2011. 60.2\% of these cases originated from Plasmodium vivax (unpublished) and the other 39.8\% came from Plasmodium falciparum (39.3\%) and $P$. ovale $(0.5 \%)$. In 2010, the annual malaria incidence

\section{Biomed Central}


rate in Yingjiang county of Yunnan province was 14.25 cases per 10000 people [3]. In the Kachin State of Myanmar, the rate was 21.7 cases/1000 people in 2006, and this area also had a high malaria-related mortality rate of 7.8 deaths/1000 people in 2005 [4].

Due to the outbreak of malaria, seasonal migrant workers, forest-related workers, pregnant women, $<5$ year-old children and miners have become high risk groups [5]. They continually cross the border to visit their relatives, trade goods or do other activities. They often contact malaria while travelling, resulting in an increase in imported malaria cases. For instance, one-third of malaria cases in China came from Yunnan province in 2005, and approximately a quarter of these were initially infected in Myanmar during trips to visit relatives and conduct business [6]. Up to now, most villagers live in wood dwellings with a thatched roof that mosquitoes can freely pass through. Many villagers have a low economic status and suffer from malnutrition. Moreover, there have been many regional wars between the Kachin Independence Organization and the central Union Government resulting in poverty and lack of development for the local population. Controlling malaria and providing effective treatment is problematic. Thus, malaria is a severe social and health problem in this border area between China and Myanmar.

Malaria has always been a serious public health problem, and the $A n$. minimus complex and $A n$. dirus s.l. have been reported as the malaria vectors in other regions of Myanmar, Yunnan and Hainan provinces of China, and are widespread all over the South and South-East Asia and southern China including the Ryukyu archipelago of Japan [7-11]. Previous studies around the border region have been carried out in 2007 [12,13]. Hardly any specific studies have focused on this area, and the local Anopheles community (species composition) and malaria vectors remained unknown.

The goals of the present research were to clarify the community of the local Anopheles community, survey the seasonality of predominant Anopheles species, investigate the preference of blood meal and the rate of infection with the Plasmodium parasite in Anopheles mosquitoes, and ultimately ascertain the main malaria vector and assess the significance of $A n$. minimus s.l. for malaria transmission.

\section{Methods}

\section{Study area}

This study was carried out from May 2012 to April 2013 in four villages in a China- Myanmar border area (Figure 1). Two villages each were located around Nabang town in Yingjiang county of China and in the Kachin region of Myanmar, respectively, namely Nabang $\left(24^{\circ} 72^{\prime} 63^{\prime \prime} \mathrm{N}\right.$, 97 57’27”E), Daonong (24 67’05”N, 97 58'49”E), and Mung Seng Yang $\left(24^{\circ} 72^{\prime} 77^{\prime \prime N}, 97^{\circ} 55^{\prime} 68^{\prime \prime} \mathrm{E}\right)$ and Ja Htu Kong $\left(24^{\circ} 70^{\prime} 63^{\prime \prime} \mathrm{N}, 97^{\circ} 56^{\prime} 60^{\prime \prime} \mathrm{E}\right)$. The altitude of this mountainous district ranges between 180 and 1,200 m above sea level (mean: $240 \mathrm{~m}$ ). This area belongs to a tropical rainy climate and is divided into a rainy season from May to October and a dry season from November to April. The average annual temperature is $22.7^{\circ} \mathrm{C}$ and the annual rainfall is $2,655 \mathrm{~mm}$. Almost all investigated villages are located along the boundary river, the Lazan river. These villages are inhabited by people of the Jingpo nationality.

\section{Sample collection}

CDC Mini light traps using incandescent lights (model 2836BQ, BioQuip Products, Inc. USA) were deployed for mosquito collection under roofs near the main entry door inside the house, which had no carbon-dioxide or other attractants for augmentation. During the study period, one village each in China and Myanmar was chosen to collect mosquitoes every three days, and 12 houses were selected randomly to trap mosquitoes in each village. Traps were set up between 19:00 and 07:00. Each morning, mosquitoes from the light traps were killed using ethyl acetate and subsequently counted. Anopheles mosquitoes were sorted and identified according to morphological characteristics using the keys compiled by Lu BL [14] and Dong XS [15]. Due to the existence of sibling species, the collected mosquitoes were morphologically identified by species complex rather than at species level. The cryptic species may be hidden based on morphological identification alone. After identifying the specimens, each mosquito was preserved in a plastic vial $(1.5 \mathrm{ml})$ using absolute alcohol and stored at $-20^{\circ} \mathrm{C}$ in preparation for DNA extraction, capped with silica gel, and subsequently taken to the laboratory.

\section{DNA extraction}

All female adults of $A n$. minimus were firstly identified by morphology before DNA extraction. The DNA was extracted from the abdomen of each mosquito for further species confirmation and blood-meal identification using multiplex PCR. Pooled samples comprising 10 thoraxes separated from female adult bodies were combined to extract the DNA for sporozoite identification [16,17]. DNA was isolated using a DNeasy Blood \& Tissue Kit (Qiagen, Shanghai Co Ltd, China) with the extraction procedure following the tissue extraction protocol provided by the manufacturer's instructions.

\section{Species identification by multiplex PCR}

Specimens of $A n$. minimus s.l. were distinguished and identified by multiplex PCR. 50 An. minimus specimens were selected from each village. The protocol was from Phuc et al. [18] and the primers were designed based on sequence variations in the second internal transcribed spacer (ITS2) of the ribosomal DNA (rDNA). The reaction mix consisted of $12.5 \mu \mathrm{l}$ of $2 \times$ Taq Master Mix, $0.5 \mu \mathrm{l}$ of 


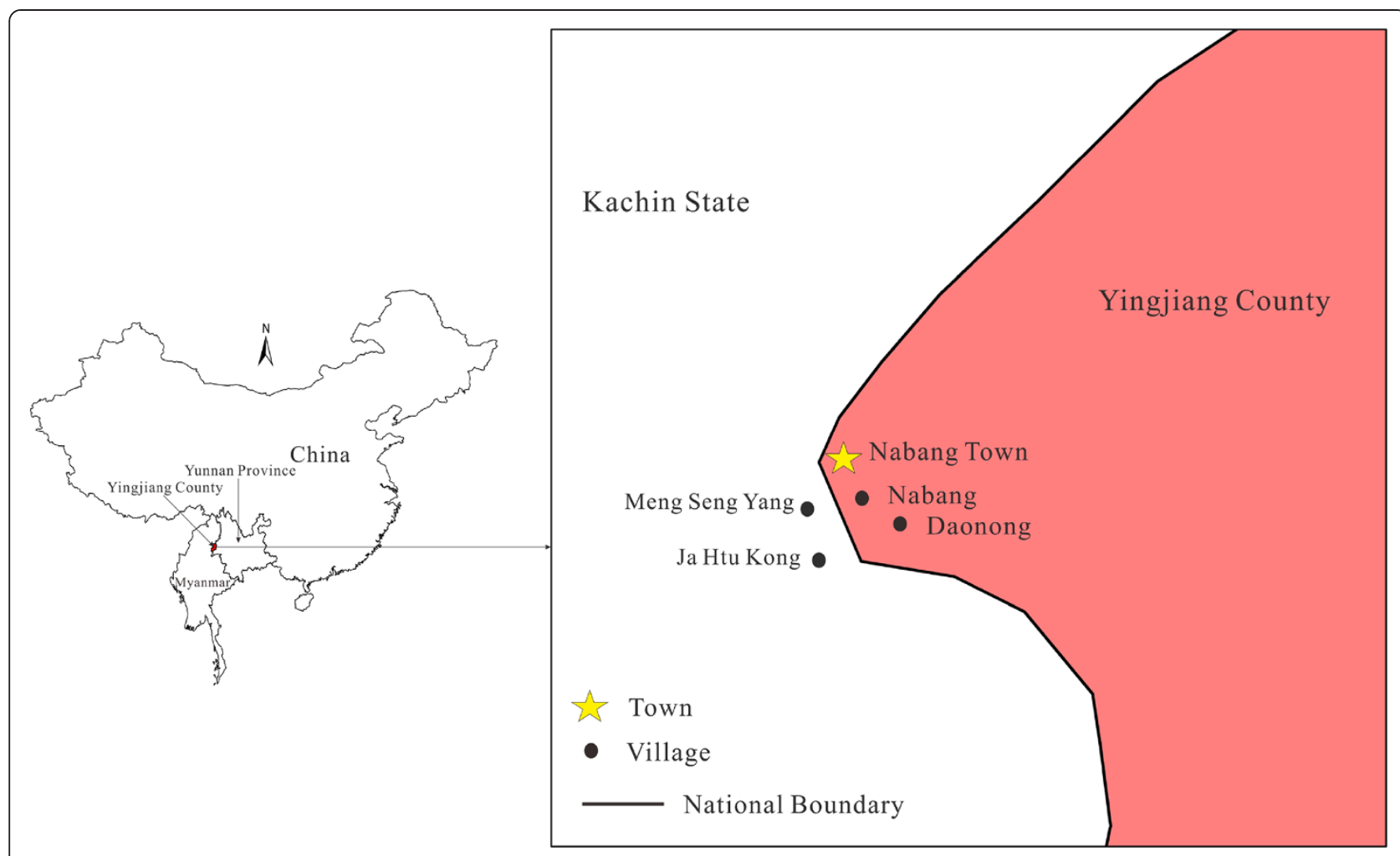

Figure 1 The map of sample collecting sites in the China-Myanmar border area.

5.8S forward, An. minimus and An. harrisoni primers (Table 1), $1 \mu \mathrm{l}$ of template DNA and $10 \mu \mathrm{l}$ of RNase free water, making a final reaction volume of $25 \mu \mathrm{l}$. PCR was performed under the conditions: $94^{\circ} \mathrm{C}$ for $5 \mathrm{~min}$ followed by 34 cycles of $94^{\circ} \mathrm{C}$ for 45 seconds, $51^{\circ} \mathrm{C}$ for 45 seconds, $72^{\circ} \mathrm{C}$ for 45 seconds and a final extension at $72^{\circ} \mathrm{C}$ for $10 \mathrm{~min}$. An. minimus and An. harrisoni were characterized by $184 \mathrm{bp}$ and $509 \mathrm{bp}$ fragments. The $2 \mu \mathrm{l}$ of PCR products were subjected to electrophoresis on a $1.5 \%$ agarose gel for
An. minimus and An. harrisoni, and stained with ethidium bromide for visual detection using the Gel Imaging System (ChemiDoc $\left.^{\mathrm{Tm}} \mathrm{XRS}+, \mathrm{BIO}-\mathrm{RAD}, \mathrm{USA}\right)$. If there was an expected result, the remaining sample of the amplified products was sequenced in both directions for confirmation.

\section{Blood-meal identification by multiplex PCR}

The identification of blood sources was carried out by using multiplex PCR as described by Kent et al. [19], with

Table 1 Primers used for multiplex PCR and nested PCR

\begin{tabular}{|c|c|c|c|c|}
\hline Species & Primer name & Sequences $\left(5^{\prime}\right.$ to $\left.3^{\prime}\right)$ & Amplification size (bp) & Sources \\
\hline Forward primer for Anopheles & ANF & ATCACTCGGCTCATGGATCG & & Phuc et al. (2003) \\
\hline An. minimus & MAR & GGGCGCCATGTAGTTAGAGTTG & 184 & \\
\hline An. harrisoni & MCR & GGTTGCCCACTCAATACGGGTG & 509 & \\
\hline Reverse primer for animal & UNR & GGTTGTCCTCCAATTCATGTTA & & Kent et al. (2005) \\
\hline Human & HUF & GGCTTACTTCTCTTCATTCTCTCCT & 335 & \\
\hline Cow & COF & CATCGGCACAAATTTAGTCG & 561 & \\
\hline Pig & PIF & CCTCGCAGCCGTACATCTC & 453 & \\
\hline Dog & DOF & GGAATTGTACTATTATTCGCAACCAT & 680 & \\
\hline \multirow[t]{2}{*}{ P. falciparum } & PFF & TTAAACTGGTTTGGGAAAACCAAATATATT & 205 & Snounou et al. (1993) \\
\hline & PFR & ACACAATGAACTCAATCATGACTACCCGTC & & \\
\hline \multirow[t]{2}{*}{ P. vivax } & PVF & CGCTTCTAGCTTAATCCACATAACTGATAC & 121 & \\
\hline & PVR & ACTTCCAAGCCGAAGCAAAGAAAGTCCTTA & & \\
\hline
\end{tabular}


primers designed based on sequence differences in the cytochrome $b$ of the mitochondrial DNA (mtDNA). Abdomens of blood-fed An. minimus were chosen with up to 50 from each site. When a site was too skimpy to select 50 abdomens, as many as possible blood-meals of An. minimus complex were selected. The volume system of the PCR reaction was similar to the species identification except for the primers used. Amplification was performed under the following conditions: $95^{\circ} \mathrm{C}$ for $5 \mathrm{~min}$ followed by 34 cycles of $95^{\circ} \mathrm{C}$ for $1 \mathrm{~min}, 55^{\circ} \mathrm{C}$ for $1 \mathrm{~min}, 72^{\circ} \mathrm{C}$ for $1 \mathrm{~min}$ and a final extension at $72^{\circ} \mathrm{C}$ for $10 \mathrm{~min}$. A sample was considered positive when any fragments of four animals were detected. All PCR products were cloned, sequenced and blasted using NCBI BLAST.

\section{Sporozoite detection by nested PCR}

The detection of sporozoites was adapted from the nested PCR described by Snounou et al. [20]. The following primer pairs were used: the plasmodium specific SSUrDNA primers rPLU5 (5'-CCTGTTGTTGCCTTAAACTTC-3') and rPLU6 (5' -TTAAAATTGTTGCAGTTAAAACG-3'), which were used in an initial amplification reaction. The size of the DNA target is about 1,200 bp. These primers are genus specific and can amplify the target sequences from all four species of human malaria parasite, Plasmodium falciparum, P. vivax, P. malariae and P. ovale. The Plasmodium parasite species-specific SSUrDNA primers rFAL1, rFAL2, rVIV1 and rVIV2 were used for the specific detection of $P$. falciparum and P. vivax (Table 1). In the first round, DNA amplification followed the protocol: $10 \mu \mathrm{l}$ of $2 \times$ Taq Master Mix, $1 \mu \mathrm{l}$ of rPLU5 and rPLU6 primers, $4 \mu \mathrm{l}$ of template DNA, mixing in $20 \mu \mathrm{l}$ final capacity with $4 \mu \mathrm{l}$ of RNase free water. For the Nest 2, $2 \mu \mathrm{l}$ of Nest 1 PCR products were used as the template for the second amplification where two pairs of species specific primers must be added. Amplification was performed under the following conditions: 2 minutes initial denaturation at $94^{\circ} \mathrm{C}, 30$ cycles of 30 seconds at $94^{\circ} \mathrm{C}, 30$ or 120 seconds at $58^{\circ} \mathrm{C}$, and 120 seconds at $72^{\circ} \mathrm{C}$, and a 5 minute final extension at $72^{\circ} \mathrm{C}$. Nest 1 and 2 both obeyed this volume system and PCR procedure, with a small difference in the time at annealing temperature. Pooled samples were regarded as positive results if any fragment of $121 \mathrm{bp}$ and 205 bp was obtained in the Nest 2.

\section{Results}

Species composition and Anopheles minimus's seasonality During the year, a total of 4,833 adult Anopheles mosquitoes were collected using CDC light traps in households throughout the four villages. Among the collected mosquitoes, 13 species were identified based on morphological characteristics (Table 2). An. minimus s.l. was the predominant species representing $78.83 \%$ of the total number of trapped Anopheles mosquitoes, followed by An. maculatus
(5.55\%) and An. culicifacies complex (4.03\%). Because of the small number of 37 An. minimus specimens collected in Daonong village throughout the year, a total of 187 morphologically-identified $A n$. minimus s.l. were randomly selected for species confirmation by multiplex PCR followed by sequencing; all detected $A n$. minimus specimens were confirmed as $A n$. minimus based on the 184 bp fragment (Figure 2). Therefore, An. minimus was regarded as the only member of the complex in this region. This sequence was also blasted in NCBI for identification, and the result revealed a homology of $99 \%$ between the 184 bp fragment and the $A n$. minimus sequence.

The relative abundance of $A n$. minimus s.l. varied throughout the year (Figure 3 ). Obviously the number of collected $A n$. minimus in the rainy season of malaria transmission was greater than in the non-malarial dry season, and one high peak of abundance was found in May 2012 and the low peak period ranged from December 2012 to February 2013.

\section{Blood meal origin of An. minimus}

Unfortunately, we failed to obtain any blood-meal in $A n$. minimus from Daonong using the light traps, and only 4 blood-meal $A n$. minimus s.l. specimens were collected in Nabang in the present study. Overall, 104 An. minimus specimens engorged with fresh blood from four villages were randomly selected to detect their blood meal source and identify the host species (Figure 2). The results show that 104 specimens confirmed as An. minimus gave positive reactions against human, cow, pig, dog or multiple antibodies (Table 3). Of all mosquitoes analysed, human beings were the primary host for blood meals accounting for $82.69 \%$ of the total number of detected specimens; this is significantly higher than other hosts. The proportion of cattle was $8.65 \%$, pigs $4.81 \%$ and dogs $3.85 \%$. In addition, $0.96 \%$ was discovered positive for blended blood meals of human and pig, and the mix of human and cow was also $0.96 \%$. Therefore, the human blood index (HBI) of $82.69 \%$ for $A n$. minimus, including mixed blood meals, was higher than the blood indices for cattle, pigs and dogs.

\section{Sporozoite detection}

A 121 bp fragment was amplified from one of the 150 pooled An. minimus samples (Figure 2). According to Snounou et al. [20] and Zakeri et al. [21], electrophoresis on a $1.5 \%$ agarose gel of the nested PCR products confirmed the existence of the $P$. vivax SSUrDNA fragment which was found to match with the previously reported result [20]. PCR analysis for detection of the Plasmodium genus and species determination established that the percentage of $P$. vivax infection was $0.07-0.7 \%$. 
Table 2 Community composition and individual percentage of Anopheles species in China-Myanmar border area

\begin{tabular}{llllll}
\hline Species & $\begin{array}{l}\text { Number of } \\
\text { individuals }\end{array}$ & $\begin{array}{l}\text { Individual } \\
\text { percentage }\end{array}$ & Species & $\begin{array}{l}\text { Number of } \\
\text { individuals }\end{array}$ & $\begin{array}{l}\text { Individual } \\
\text { percentage }\end{array}$ \\
\hline An. minimus & 3810 & 78.83 & An. peditaeniatus & 44 & 0.91 \\
An. maculatus & 268 & 5.55 & An. sinensis & 39 & 0.81 \\
An. culicifacies & 195 & 4.03 & An. kochi & 23 & 0.48 \\
An. jeyporiensis & 134 & 2.77 & An. tessellatus & 12 & 0.25 \\
An. vagus & 129 & 2.67 & An. messeae & 3 & 0.06 \\
An. splendidus & 104 & 2.15 & An. annularis & 2 & 0.04 \\
An. barbirostris & 70 & 1.45 & & & \\
\hline
\end{tabular}

\section{Discussion}

In this study, we report our investigation of the Anopheles community and the role of An. minimus in malaria transmission in a region along the Sino-Myanmar border. According to our results, the Anopheles community in this district consists mostly of the primary vector $A n$. minimus s.s. (occupying $78.83 \%$ ) with another 12 Anopheles species accounting for $21.17 \%$. A previous study reported the mosquito community near the China-Myanmar border in the western Yunnan, which included 12 Anopheles species with An. sinensis (accounting for 25.9\%) being the most abundant species but Culex tritaeniorhynchus (67.9\%) in this investigation [12]. However, the right China-Myanmar border area has a different environment and consequently different mosquito community composition, and the bloodmeal and sporozoite of Anopheles mosquitoes have never been investigated before. Although several reports had confirmed that $A n$. sinensis and $A n$. minimus were among the major malaria vectors in China and Myanmar [22-25], there was no prior direct evidence for malaria transmission by the two species in this malaria prone area. The An. dirus complex has been reported in Myanmar [24] but it was not collected during this year-long study in this border region. Thus, An. minimus was regarded as the dominant endemic vector.

Because of the spread of the war between the KIO and the Central Union Government in this area between January and February 2013, work on mosquito collection was compelled to stop. Thus, complete data on seasonal variation during these two months was absent (Figure 3). Clearly $A n$. minimus was seasonal in this border region where the warm and wet months of May-October were the peak season and the cold and dry months of November-April were the off season. The quantity of An. minimus in the rainy season far outstripped that in dry season. Meanwhile, An. minimus's seasonality positively correlated with malaria occurrence in this district. Thus, effective preventive measures including free provision of

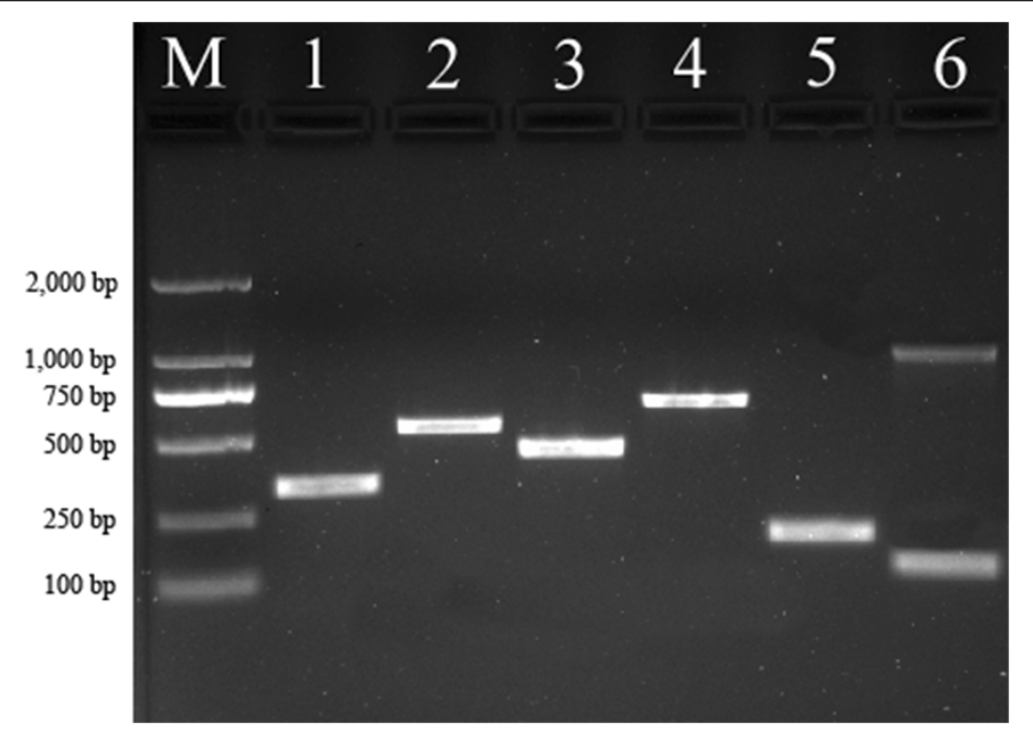

Figure 2 PCR identification of Anopheles minimus s.l. species, blood-meal source and sporozoites. The sizes of ethidium bromide-stained PCR products from multiplex PCR and nested PCR, examined by electrophoresis on agarose gel, served as the identification standard. Lane M: 2,000 bp ladder; lane 1: human; lane 2: cow; lane 3: pig; lane 4: dog; lane 5: An. minimus; lane 6: P. vivax. 


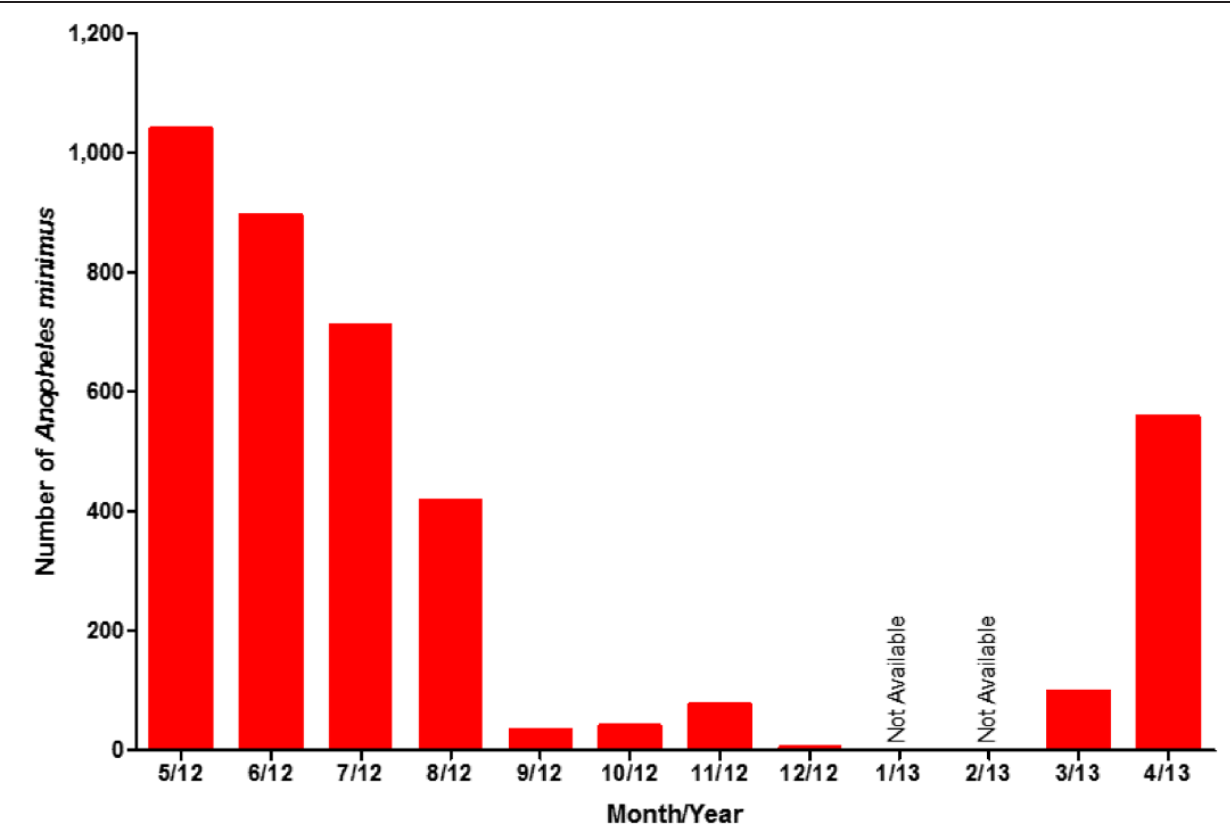

Figure 3 Monthly abundance of Anopheles minimus in the China-Myanmar border area.

bed nets and insecticide spray for each family must be available and implemented in a timely manner during the rainy period.

The research further indicates that $A n$. minimus shows a variable behavior on blood meal. An. minimus s.l. comprised three sibling species, namely $A n$. minimus, An. harrisoni Harbach \& Manguin and An. yaeyamaensis Somboon \& Harbach [26-28]. An. minimus and $A n$. harrisoni have a broad distribution in much of Southeast Asia and Southern China [7]. However, most studies did not differentiate $A n$. minimus and $A n$. harrisoni on blood source detection. More investigations are required on $A n$. minimus and $A n$. harrisoni throughout an extensive geographical area where the $A n$. minimus complex has existed. The $A n$. minimus complex is either zoophilic or anthropophilic, depending on the local host availability. In this study, An. minimus fed on four animal's (humans, cattle, pigs and dogs) distinguished by multiplex PCR. This population of An. minimus showed a greater bias for humans. The results of the high HBI for An. minimus is in line with previous research [11]. The high human preference of $82.69 \%$ suggests that malaria transmission tends to occur in this malaria epidemic region. The numbers for sites Daonong (37 individuals) and Nabang (275) are quite small, mainly because both are located in south-western Yunnan, where insecticide spray for each family was timely carried out and different economic crop planting resulted in adverse ecological environments for mosquitoes.

The identification of Plasmodium parasites in the salivary glands of $A n$. minimus s.l. conclusively identified them as malaria vectors. Sporozoite infection rates were traditionally detected by dissection and inspection of the salivary glands of each mosquito under a light microscope. Molecular methods have been established in recent years, including the PCR method [29,30] aiming at amplifying specific DNA sequences for detection and CSP-ELISA detecting the circum sporozoite protein $[11,31,32]$. They

Table 3 The numbers of total and blood-meal individuals from 4 collecting sites for An. minimus

\begin{tabular}{lllllllll}
\hline \multirow{2}{*}{ Collection sites } & \multirow{2}{*}{$\begin{array}{l}\text { Total } \\
\text { number }\end{array}$} & \multicolumn{2}{l}{ Number of blood-meal individuals } \\
\cline { 2 - 8 } & Total (HB|*,\%) & Human (\%) & Cow (\%) & Pig (\%) & Dog (\%) & Human + Cow (\%) & Human + Pig (\%) \\
\hline Daonong & 37 & $0(0)$ & $0(0)$ & $0(0)$ & $0(0)$ & $0(0)$ & $0(0)$ & $0(0)$ \\
Nabang & 275 & $4(25)$ & $1(25)$ & $2(50)$ & $0(0)$ & $1(25)$ & $0(0)$ & $0(0)$ \\
Meng Seng Yang & 922 & $50(86)$ & $41(82)$ & $4(8)$ & $2(4)$ & $1(2)$ & $1(2)$ & $1(2)$ \\
Ja Htu Kong & 2576 & $50(84)$ & $42(84)$ & $3(6)$ & $3(6)$ & $2(4)$ & $0(0)$ & $0(0)$ \\
Total & 3810 & $104\left(82.69^{\S}\right)$ & $84(80.77)$ & $9(8.65)$ & $5(4.81)$ & $4(3.85)$ & $1(0.96)$ & $1(0.96)$ \\
\hline
\end{tabular}

* $\mathrm{HBI}$ - Human blood index. The number of Human + Cow and Human + Pig blood meals were added to the number of human blood meals when calculating the $\mathrm{HBI} .{ }^{\S}$ Overall $\mathrm{HBI}$ of Anopheles minimus. 
have both advantages and disadvantages. In this study, a nested PCR method based on the amplification of the SSUrDNA of $P$. vivax sporozoites was selected to identify malaria vectors. This is a highly sensitive, conventional and effective approach. One of 150 pooled samples was confirmed positive in mosquito salivary glands by using this tool. It appears that $A n$. minimus is the predominant malaria vector in this region.

In view of the findings of this study, An. maculatus, An. jeyporiensis, An. culicifacis complex and An. sinensis, the major malaria vectors reported in Thailand [33,34], India and Sri Lanka [35,36], and central China [37], respectively, are less abundant. That is not to say that these minor Anopheles populations do not have a potential vectorial role in the transmission of malaria in this boundary region. For instance, An. maculatus complex was infected by Plasmodium and also detected in Yunnan Province in south-west China [38]. They may be potential secondary malaria vectors and further research is required to understand the relationship between these Anopheline mosquitoes and malaria outbreaks. Malaria transmission will continue to be influenced by environmental changes, wars, dwelling conditions and human activities including visiting families and conducting making trade. Ultimately, this study provides baseline information for local evidencebased malaria control programmes, reveals valuable information necessary for the implementation of prospective control strategies, and will be useful to other regions or countries dealing with similar high burdens of malaria.

\section{Conclusion}

The diversity of Anopheles mosquitoes on the ChinaMyanmar border area was abundant with 13 Anopheles species being identified based on morphological and/or molecular characteristics. An. minimus was the dominant species with a much higher human blood index compared to other animals in this area. Additionally, An. minimus was confirmed as the local malaria vector but with low sporozoite infection detected.

\section{Competing interests}

The authors declare that they have no competing interests.

\section{Authors' contributions}

$\mathrm{BC}, \mathrm{GY}$ and DZ conceived and designed the study, and BC also helped in performing data analysis and drafting the manuscript. Guo Yu designed the experiments, performed the study and drafted the manuscript. NZ, YW, ZH, $Z Y, W F$ and FY joined the specimens collecting and experiments. All authors read and approved the final version of the manuscript.

\section{Acknowledgements}

This work was supported by grants from The National Natural Science Foundation of China (31071968 and 31372265), grants from the National Institute of Health (R01 Al095184 and R03 TW008237), Key Scientific and Technological Project of Chongqing (CSTC2012GG-YYJSB80002) and Par-Eu Scholars Program. Many thanks to Prof. John Richard Schrock of Emporia State University, USA for English revision.

\section{Author details}

${ }^{1}$ Institute of Entomology and Molecular Biology, College of Life Sciences, Chongqing Normal University, Chongqing, P.R. China. ${ }^{2}$ Program in Public Health, College of Health Sciences, University of California, Irvine, California, USA. ${ }^{3}$ Department of Pathogenic Biology, College of Medicine, Third Military Medical University, Chongqing, China.

Received: 29 June 2013 Accepted: 7 September 2013

Published: 13 September 2013

\section{References}

1. WHO: World Malaria Report 2012. Geneva: World Health Organization; 2012.

2. Cui L, Yan G, Sattabongkot J, Cao Y, Chen B, Chen X, Fan Q, Fang Q, Jongwutiwes S, Parker D, et al: Malaria in the Greater Mekong Subregion: heterogeneity and complexity. Acta Trop 2012, 121(3):227-239.

3. Zhou SS, Wang Y, Tang LH: Malaria situation in the People's Republic of China in 2010. Chin J Parasitol Parasit Dis 2011, 29:401-403.

4. WHO: Malaria in the Greater Mekong Subregion: Regional and Country Profiles. Geneva: World Health Organization; 2010.

5. ADB: Technical assistance for the study of the health and educational needs of ethnic minorities in the Greater Mekong Sub region. Manila: Asian Development Bank; 1998.

6. Fund G: East Asia and Pacific regional overview: successes, challenges and achievements to date. Geneva: The Global Fund to Fight AIDS, Tuberculosis and Malaria; 2007.

7. Manguin S, Garros C, Dusfour I, Harbach RE, Coosemans M: Bionomics, taxonomy, and distribution of the major malaria vector taxa of Anopheles subgenus Cellia in Southeast Asia: an updated review. Infect Genet Evol 2008, 8(4):489-503.

8. Sinka ME, Bangs MJ, Manguin S, Chareonviriyaphap T, Patil AP, Temperley WH, Gething PW, Elyazar IR, Kabaria CW, Harbach RE, et al: The dominant Anopheles vectors of human malaria in the Asia-Pacific region: occurrence data, distribution maps and bionomic precis. Parasit Vectors 2011, 4:89.

9. Garros C, Van Bortel W, Trung HD, Coosemans M, Manguin S: Review of the minimus complex of Anopheles, main malaria vector in Southeast Asia: from taxonomic issues to vector control strategies. Trop Med Int Health 2006, 11(1):102-114.

10. Chen B, Harbach RE, Butlin RK: Molecular and morphological studies on the Anopheles minimus group of mosquitoes in southern China: taxonomic review, distribution and malaria vector status. Med Vet Entomol 2002, 16(3):253-265.

11. Trung HD, Bortel W, Sochantha T, Keokenchanh K, Quang NT, Cong LD, Coosemans M: Malaria transmission and major malaria vectors in different geographical areas of Southeast Asia. Trop Med Int Health 2004, 9(2):230-237.

12. Feng Y, Fu S, Zhang H, Li M, Zhou T, Wang J, Zhang Y, Wang H, Tang Q, Liang G: Distribution of mosquitoes and mosquito-borne viruses along the China-Myanmar border in Yunnan Province. Jpn J Infect Dis 2012, 65(3):215-221

13. Wu S, Pan JY, Wang XZ, Zhou SS, Zhang GQ, Liu Q, Tang LH: Anopheles pseudowillmori is the predominant malaria vector in Motuo County, Tibet Autonomous Region. Malaria J 2009, 8:5.

14. Lu BL: Fauna Sinica, Insecta, Diptera: Culicidae I/ Volume 9. Beijing China: Science Press; 1997.

15. Dong XS: The Mosquito Fauna of Yunnan China: Volume 1. Yunnan China: Yunnan Science \& Technology Press; 2010.

16. Li FW, Niu C, Ye BH: Nested polymerase chain reaction in detection of Plasmodium vivax sporozoites in mosquitoes. Chin Med J 2001, 114:654-657.

17. Sun QW, Zhu HM, Lu L, Gu ZC, Cheng X, Fang Y: Restudy on a model for estimating the sporozoite infection rate in mosquitoes using pooled sampling. Chin J Parasitol Parasit Dis 2002, 20:351-353.

18. Phuc HK, Ball AJ, Son L, Hanh NV, Tu ND, Lien NG, Verardi A, Townson H: Multiplex PCR assay for malaria vector Anopheles minimus and four related species in the Myzomyia Series from Southeast Asia. Med Vet Entomol 2003, 17(4):423-428.

19. Kent RJ, Norris DE: Identification of mammalian blood meals in mosquitoes by a multiplexed polymerase chain reaction targeting cytochrome B. Am J Trop Med Hyg 2005, 73(2):336-342. 
20. Snounou G, Viriyakosol S, Zhu XP, Jarra W, Pinheiro L, do Rosario VE, Thaithong S, Brown KN: High sensitivity of detection of human malaria parasites by the use of nested polymerase chain reaction. Mol Biochem Parasitol 1993, 61(2):315-320.

21. Zakeri S, Najafabadi ST, Zare A, Djadid ND: Detection of malaria parasites by nested PCR in south-eastern, Iran: evidence of highly mixed infections in Chahbahar district. Malaria J 2002, 1:2.

22. Liu C: Comparative studies on the role of Anopheles anthropophagus and Anopheles sinensis in malaria transmission in China. Chin J Epidemiol 1990, 11:360-363.

23. Sleigh $A C$, Liu XL, Jackson S, Li P, Shang LY: Resurgence of vivax malaria in Henan Province, China. Bull World Health Organ 1998, 76:265-270.

24. Oo TT, Storch $V$, Becker N: Review of the Anopheline mosquitoes of Myanmar. J Vector Ecol 2004, 29(1):21-40.

25. Myo P, Tun Lin W, Sebastian AA: Behavior of Anopheles minimus (Theobald) in relation to its role as vector of malaria in a forested foothill area of Burma. Trop Biomed 1988, 5(2):161-166.

26. Harbach RE, Garros C, Manh ND, Manguin S: Formal taxonomy of species $\mathrm{C}$ of the Anopheles minimus sibling species complex (Diptera: Culicidae). Zootaxa 2007, 1654:41-54

27. Harbach RE, Parkin E, Chen B, Butlin RK: Anopheles (Cellia) minimus Theobald (Diptera: Culicidae): neotype designation, characterization, and systematics. Proc Entomol Soc Wash 2006, 108:198-209.

28. Somboon P, Rory A, Tsuda Y, Takagi M, Harbach RE: Systematics of Anopheles (Cellia) yaeyamaensis sp. n., alias species E of the An. minimus complex of southeastern Asia (Diptera: Culicidae). Zootaxa 2010, 2651:43-51.

29. Stoffels JA, Docters van Leeuwen WM, Post RJ: Detection of Plasmodium sporozoites in mosquitoes by polymerase chain reaction and oligonucleotide rDNA probe, without dissection of the salivary glands. Med Vet Entomol 1995, 9:433-437.

30. Moreno M, Cano J, Nzambo S, Bobuakasi L, Buatiche JN, Ondo M, Micha F, Benito A: Malaria panel assay versus PCR: detection of naturally infected Anopheles melas in a coastal village of Equatorial Guinea. Malaria J 2004, 3:20.

31. Wirtz RA, Burkot TR, Graves PM, Andre RG: Field evaluation of enzymelinked immunosorbent assays for Plasmodium falciparum and Plasmodium vivax sporozoites in mosquitoes (Diptera: Culicidae) from Papua New Guinea. J Med Entomol 1987, 24(4):433-437.

32. Wirtz RA, Zavala F, Charoenvit Y, Campbell GH, Burkot TR, Schneider I, Esser $\mathrm{KM}$, Beaudoin RL, Andre RG: Comparative testing of monoclonal antibodies against Plasmodium falciparum sporozoites for ELISA development. Bull World Health Organ 1987, 65(1):39-45.

33. Loong KP, Chiang GL, Eng KL, Chan ST, Yap HH: Survival and feeding behaviour of Malaysian strain of Anopheles maculatus Theobald (Diptera: Culicidae) and their role in malaria transmission. Trop Biomed 1990, 7(1):71-76.

34. Vythilingam I, Foo LC, Chiang GL, Chan ST, Eng KL, Mahadevan S, Mak JW, Singh Kl: The impact of permethrin impregnated bednets on the malaria vector Anopheles maculatus (Diptera: Culicidae) in aboriginal villages of Pos Betau Pahang, Malaysia. SEt Asian J Trop Med Public Health 1995, 26(2):354-358.

35. Ramasamy R, Ramasamy MS, Wijesundera DA, Wijesundera AP, Dewit I Ranasinghe C, Srikrishnaraj KA, Wickremaratne C: High seasonal malaria transmission rates in the intermediate rainfall zone of Sri Lanka. Ann Trop Med Parasitol 1992, 86(6):591-600.

36. Subbarao SK: The Anopheles culicifacies complex and control of malaria. Parasitol Today 1988, 4(3):72-75.

37. Chow CY: Malaria vectors in China. Chin J Entomol 1991, Special Publ (6):67-79.

38. Zhou HN, Zhang ZX, Curtis C, Hill N, Li CF, Wu C, Wang PY: Evaluation of the enzyme-linked immunosorbant assay in detecting circumsporozoite protein of anopheline vectors in Yunnan. Chin J Parasitol Parasit Dis 2004, 22(4):227-230

doi:10.1186/1756-3305-6-264

Cite this article as: Yu et al:: The Anopheles community and the role of Anopheles minimus on malaria transmission on the China-Myanmar border. Parasites \& Vectors 2013 6:264.

\section{Submit your next manuscript to BioMed Central and take full advantage of:}

- Convenient online submission

- Thorough peer review

- No space constraints or color figure charges

- Immediate publication on acceptance

- Inclusion in PubMed, CAS, Scopus and Google Scholar

- Research which is freely available for redistribution 